\title{
Recovery of deformation substructure and coarsening of particles on annealing severely plastically deformed Al-Mg-Si alloy and analysis of strengthening mechanisms
}

\author{
I. Gutierrez-Urrutia, M.A. Muñoz-Morris, and D.G. Morris ${ }^{\text {a) }}$ \\ Department of Physical Metallurgy, Centro Nacional de Investigaciones Metalurgicas (CENIM), \\ Consejo Superior de Investigacion Cientifica (CSIC), E-28040 Madrid, Spain
}

(Received 11 April 2005; accepted 6 July 2005)

\begin{abstract}
An $\mathrm{Al}-\mathrm{Mg}-\mathrm{Si}$ alloy was annealed to various solutionized and aged states and was then severely plastically deformed by equal channel angular pressing (ECAP). These materials were subsequently annealed for a range of times and temperatures to induce precipitation, dislocation recovery, and grain growth, with changes of mechanical behavior followed by tensile testing. Precipitation of excess solute was seen to occur in all cases, independent of the initial heat treated state, but the particles present appear to play only a small role in stabilizing the deformation substructure, at least until significant particle and grain coarsening has occurred, when discontinuous grain coarsening can be provoked. The strength of materials is examined, and the respective contributions of loosely arranged dislocations, many grain boundaries, and dispersed particles are deduced. It is shown that dislocation strengthening is significant in as-deformed, as well as lightly annealed materials, with grain boundary strengthening providing the major contribution thereafter.
\end{abstract}

\section{INTRODUCTION}

The severe plastic deformation of ductile alloys by processes such as equal channel angular pressing (ECAP) has now been extensively studied as a method for producing materials with very fine grain size and excellent mechanical properties with the additional promise of development as a method for the preparation of commercial-scale material quantities. ${ }^{1,2}$ Deformation to the very high levels of strain that are attained leads to the creation of a fine, submicron grain structure and very high strength with retention of good ductility. ${ }^{3-9}$ During the initial stages of deformation the substructure created is dominated by dislocation rearrangement into cells and sub-boundaries, which are mostly of rather low angle [low angle grain boundaries (LAGB) somewhat arbitrarily defined as those with boundary misorientations less than $15^{\circ}$ ]. As the extent of deformation rises to very high levels, with true strains $\eta$ of the order of 10 , there is a gradual evolution from a mostly LAGB substructure to a microstructure dominated by high angle grain boundaries (HAGB, considered as those with misorientations in excess of $\left.15^{\circ}\right) .^{7-11}$

Most of the work to date has been carried out on single-phase materials, but several studies have exam-

\footnotetext{
a) Address all correspondence to this author.

e-mail: david.morris@cenim.csic.es

DOI: $10.1557 / J M R .2006 .0063$
}

ined the role of second-phase particles, both during the deformation stage itself as well as during subsequent heat treatments. In some cases, e.g., Refs. 12 and 13, commercial alloys containing coarse dispersoid particles have been processed, with little attention given to the role of the particles, apart from their harmful effect on eventual tensile ductility. Other studies, for example, ${ }^{11}$ show that coarse dispersoid particles can lead to more inhomogeneous deformation structures and can also encourage the formation of high dislocation densities and the more rapid appearance of high angle boundaries. ${ }^{11,14,15}$ Most studies of particle-containing material deformed by ECAP consider simply the role of the second phase particles on retaining the fine grain structure during subsequent high-temperature anneals. ${ }^{3,16,17}$

There are many possible changes that may take place during deformation, however, and the evolution of structure during subsequent annealing can also be very complex. Studies of the behavior of second-phase particles during severe plastic deformation have shown, for example, the break-down of fine particles to about $10 \mathrm{~nm}$ fragments, ${ }^{18}$ and the fracture of medium-sized particles into $10-100$-nm pieces. ${ }^{19,20}$ At extremely high strain levels, it may even be possible to completely dissolve the second-phase particles initially present. ${ }^{21}$ A recent study by the present authors, ${ }^{22}$ which will be described in more detail below, showed that very fine needle precipitates (about $6 \mathrm{~nm}$ thick) could be fragmented and apparently dissolved, while larger precipitates and dispersoids (150- 
$1000 \mathrm{~nm}$ in diameter) were only slightly fractured during ECAP. Annealing such deformed materials generally leads to a recovery of the dislocation structures, with steady growth of the grain structure. ${ }^{3,9,16,23,24}$ The grain morphology will change from an elongated form typical after deformation to a more equi-axed form after annealing by both grain growth as well as the appearance of new transverse boundaries. ${ }^{3,9,23}$ Second-phase particles may also play a role in inducing a change from continuous grain coarsening, or continuous recrystallization, to discontinuous grain growth, or secondary recrystallization, leading to an inhomogeneous microstructure. ${ }^{25}$ It should also be remembered that second-phase precipitation and coarsening can occur during annealing, often with different kinetics and phase crystal structure and morphology than found during annealing of usual, undeformed materials, ${ }^{26}$ indicating the complexity of the changes occurring.

Much of the interest in severe plastic deformation arises from the very high strengths that can be achieved, especially in combination with good ductility. ${ }^{6,27}$ For the most part, this high level of strength has been explained by the very fine grain structure that is achieved, $, 6,7,28,29$ but also in terms of the high levels of internal strains and the presence of so-called non-equilibrium boundaries. $^{3,6,30}$ The mechanisms leading to strengthening are not well understood, however, and the balance between strengthening by the high density of retained dislocations and the fine grain size is not clear. ${ }^{31-34}$ The major reasons for the difficulty of analysis of strengthening arise from the wide distribution of grain boundary types present (LAGB and HAGB), which will not be expected to contribute to strengthening in the same way, ${ }^{33,34}$ and from estimating the importance of the high density of dislocations generally present.

The present study sets out to examine the influence of high-temperature anneals on the structure and mechanical properties of severely deformed samples of materials previously annealed to a variety of states, containing relatively coarse intermetallic dispersoids and either no, fine, or coarse precipitates. The role of these particles on substructure recovery and coarsening is examined, and at the same time the contributions of second-phase particles, grain boundaries, and individual dislocations to strengthening has been analyzed from the as-deformed state to the annealed and well recovered state.

\section{EXPERIMENTAL DETAILS}

The material studied was a commercial $6082 \mathrm{Al}$ alloy, nominally $\mathrm{Al}-1 \% \mathrm{Mg}-1 \% \mathrm{Si}$ with $\mathrm{Fe}, \mathrm{Mn}$, and $\mathrm{Cr}$ present as dispersoids: analyzed as $\mathrm{Al}-0.9 \% \mathrm{Mg}-1.1 \% \mathrm{Si}$, with $0.5 \% \mathrm{Fe}, 0.5 \% \mathrm{Mn}$, and $0.2 \% \mathrm{Cr}$ (by weight). This was provided as extruded bar $20 \mathrm{~mm}$ in diameter, which was given a variety of heat treatments before severe plas- tic deformation by ECAP. Precise details of treatments, ECAP procedures, and microstructures of as-annealed and as-deformed materials have been given elsewhere, ${ }^{22}$ and only a brief summary is given here. The heat treatments corresponded to the following states: state I-as solutionized, water quenched after $1 \mathrm{~h}$ at $590{ }^{\circ} \mathrm{C}$; state II-peak aged condition, solutionized followed by $30 \mathrm{~min}$ at $250{ }^{\circ} \mathrm{C}$; state III strongly overaged conditionsolutionized followed by $8 \mathrm{~h}$ at $450{ }^{\circ} \mathrm{C}$. For ECAP, cylindrical samples of diameter $20 \mathrm{~mm}$ and length $50 \mathrm{~mm}$ were lubricated with $\mathrm{MoS}_{2}$ grease and pressed through a die with an angle of $118-120^{\circ}$, producing a true strain per pass of 0.7 , as described elsewhere. ${ }^{9,22}$ Repeated pressing was carried out using the so-called route $\mathrm{A},{ }^{3,5}$ whereby there is no rotation of sample between passes, and samples processed up to a maximum of 6 passes, corresponding to a total strain of 4.2. The strain imposed is relatively low within the context of severe deformation studies, but experiments were stopped at this stage due to the initiation of surface cracking of the cylindrical samples. Following ECAP, a variety of isothermal and isochronal anneals were carried out at temperatures in the range $200-350{ }^{\circ} \mathrm{C}$ in air.

Hardness changes during ECAP and after annealing were followed by Vickers microhardness testing. Tensile testing was carried out on samples of gauge length $20 \mathrm{~mm}$ and diameter $3 \mathrm{~mm}$, with the tensile axis parallel to the ECAP pressing direction, and at a nominal strain rate of $4 \times 10^{-4} / \mathrm{s}$.

The microstructures of materials after ECAP processing and after subsequent annealing were examined by scanning electron microscopy (SEM) using a JEOL 6500F instrument (Osaka, Japan) with field emission gun and by transmission electron microscopy (TEM) using a JEOL 2010 instrument. Polished sections and thin foil samples were prepared by electropolishing using a $25 \%$ nitric acid-methanol mixture at about $-25^{\circ} \mathrm{C}$ and $14 \mathrm{~V}$. The longitudinal section was chosen for study; i.e., the observation direction was perpendicular to the inlet and outlet ECAP cylinder axes, such that the extent of microstructural elongation was clearly visible. ${ }^{9,22}$ Precipitate and dispersoid particle sizes, and matrix grain sizes, were measured from SEM or TEM images using Sigma Scan Pro 4.0 image analysis software (Jandel Scientific, San Rafael, CA) and analyzed using Excel 8 statistical programs (Excel, Microsoft, Redmond, WA).

Grain sizes were measured from SEM images obtained using backscattered electrons counting 200-300 grains per state; a standard deviation of below $5 \%$ of average value was found. Intermetallic dispersoid particles (of $\mathrm{Fe}, \mathrm{Mn}$, and $\mathrm{Cr}$ impurities), seen in light contrast, and coarse $\beta$ phase particles in material in state III, were analyzed by SEM, counting 500-1000 dispersoid particles and $\beta$ phase particles to determine average size with an error below $10 \%$ of size for both particles and 
below $20 \%$ of relative volume fraction for both. The volume fraction deduced from SEM images is taken to be the same as the measured surface fraction. Fine precipitate particles (of $\beta^{\prime \prime}$ and $\beta^{\prime}$ in annealed state II, and $\beta$ phase after annealing) were examined by TEM, and sizes determined by counting over 500 particles in each state, giving a relative error of particle size better than $10 \%$. The determination of volume fraction of the fine $\beta$ phase particles forming on annealing was difficult since these small particles could not be imaged by SEM, and measurement of sample volumes examined by TEM (requiring determination of foil thicknesses) was judged to be excessively difficult on many regions of the many annealed materials. Hence, instead, the volume fraction of such precipitates was deduced simply from the known solubility limits of the $\mathrm{Al}-\mathrm{Mg}-\mathrm{Si}$ phase diagram at the 200-300 ${ }^{\circ} \mathrm{C}$ annealing temperatures.

\section{RESULTS}

\section{A. Initial microstructure, particle sizes, and distributions}

Details of microstructures of the initial annealed materials and after severe plastic deformation have been presented before. ${ }^{22}$ Some information will be presented in the following pages but with an emphasis on the changes occurring during post-deformation annealing. Only a brief summary of the microstructural states is given here.

The as-solutionized material, state I, contained only intermetallic dispersoid particles rich in $\mathrm{Si}, \mathrm{Cr}$, and $\mathrm{Mn}$ (the significant amounts of Fe present in the alloy were not found within these many fine dispersoid particles) and had a grain size of $30 \mu \mathrm{m}$. These intermetallic particles were present in a volume fraction of $0.5 \%$, with average size of $135 \mathrm{~nm}$. Note that since these particles were rich in heavy elements (relative to the $\mathrm{Al}-\mathrm{Mg}-\mathrm{Si}$ base), they appeared light in backscattered electron images in the SEM, and it was easy to differentiate them from any ( $\mathrm{Mg}-\mathrm{Si}$ base) precipitates present at any stage of annealing. These intermetallic particles were not affected by severe deformation.

State II material, aged to peak hardening, contained, in addition to the intermetallics, $0.5 \%$ of $\beta^{\prime \prime}$ and $\beta^{\prime}$ needles which were $6 \mathrm{~nm}$ thick and 40 or $100 \mathrm{~nm}$ long. ${ }^{22}$ In State III material, severely overaged, the needle precipitates had been replaced by nearly spherical $\beta$ phase precipitates of size $1000 \mathrm{~nm}$ in a volume fraction of $0.9 \%$.

It is well established that the deformation microstructure refines steadily during severe deformation by ECAP, with a tendency to saturation of microstructure, boundary types, and mechanical properties beginning already after low ECAP strains (of the order of $2-3$ ), ${ }^{4,5,8}$ reaching close to the final structure at strain levels of 4-6, even though extremely high strains (of the order of 10) are required for true stabilization of structure. ${ }^{8}$ The present experiments, with an imposed strain of 4.2 are thus expected to produce materials with fine microstructures and mixed low/high-angle boundaries approaching the stabilized microstructural state. During the present experiments by ECAP, a gradual refinement of the grain structure was observed as the imposed strain increased to the maximum tested (6 ECAP passes, true strain $\eta$ of 4.2). At this time, the elongated grain structure was similar for all material states (I, II, and III), with a width of about $0.2 \mu \mathrm{m}$ and length of $0.5 \mu \mathrm{m}$ (precise values will be given later in this report), and the average boundary misorientation was about $20^{\circ} .{ }^{22}$

During ECAP, the dispersoids do not deform or fracture, the $\beta^{\prime \prime}-\beta^{\prime}$ needles are sheared and disappear, and the $\beta$ particles are slightly elongated and reduced in size (values will be given later here). The $\beta^{\prime \prime}-\beta^{\prime}$ needles were not detected in bright field, dark field, or weak beam electron micrographs after severe plastic deformation to a strain of 4.2. A further study after a single ECAP pass on material in state II, to a strain of 0.7 , was also unable to find remains of the initial $\beta^{\prime \prime}-\beta^{\prime}$ needle particles. The disappearance of these particles after such small strains may appear somewhat surprising. It should be recalled, however, that earlier studies ${ }^{18-21}$ showing only partial particle breakdown ${ }^{18-20}$ or eventual particle dissolution after very high strain levels ${ }^{21}$ were carried out with larger initial particle sizes which are undoubtably more difficult to dissolve than the present 6-nm-thick needle precipitates. The conclusion here is that these 6-nm-thick needles are easily fractured into short lengths, which fall in size below the critical size for dissolution.

\section{B. Changes of mechanical properties during severe plastic deformation and during subsequent annealing}

Most of the structural and property changes on annealing have been examined on materials severely plastically deformed to a high strain level (i.e., $\eta=4.2$ after 6 passes), but in addition, the influence of annealing on material previously deformed to smaller amounts of strain has also been studied.

Figure 1 shows the influence of isothermal annealing [Fig. 1(a)] and isochronal annealing [Figs. 1(b)-1(d)] on hardness and tensile properties of material in states I, II, and III (i.e., as solutionized, peak aged, and overaged) previously ECAP deformed to a strain of 4.2. At all temperatures examined, the hardness falls continuously and steadily as annealing time increases, illustrated for anneals at $250{ }^{\circ} \mathrm{C}$ in Fig. 1(a), rapidly at first and more slowly finally, approaching a near steady hardness for each state. The reduction is very similar for materials I and II but faster for material III, for which a lower level of hardness is achieved at this temperature. Figure 1(b) shows the hardness fall for $1 \mathrm{~h}$ anneals over a range of 

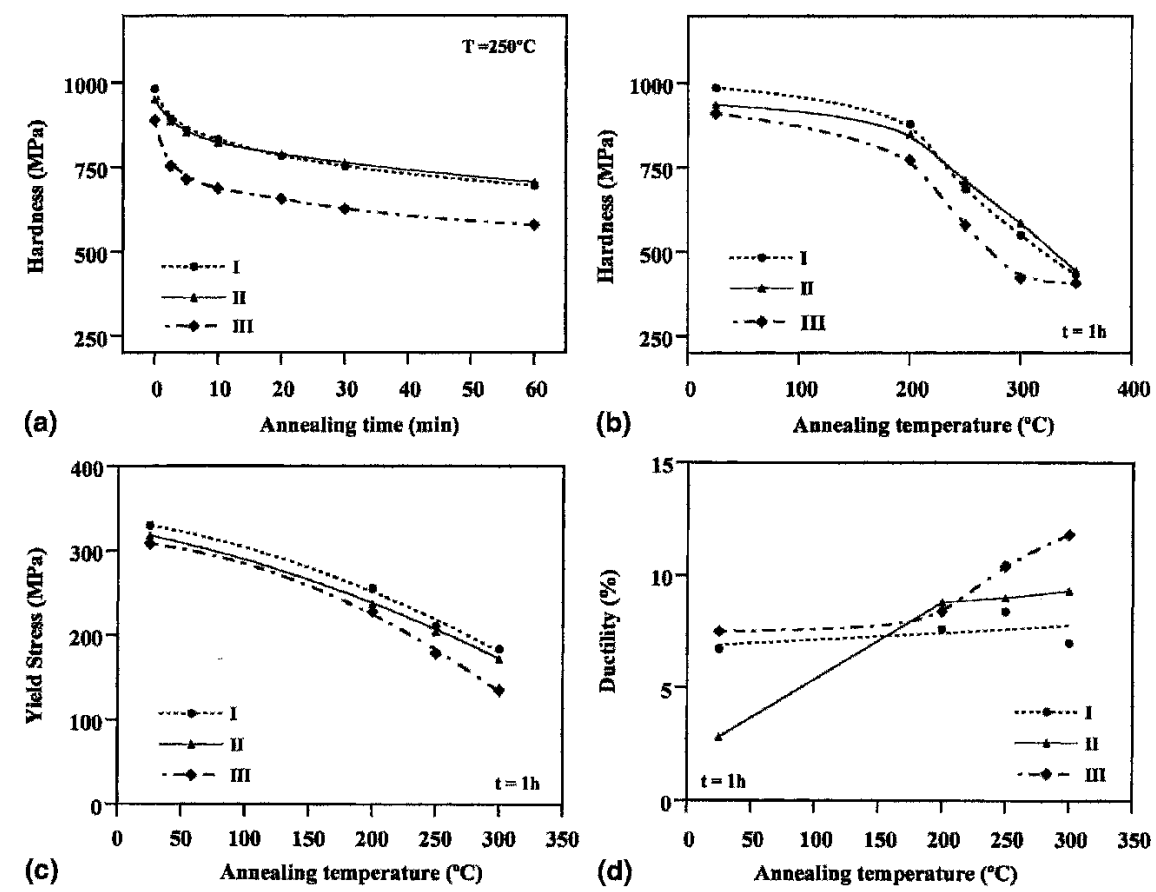

FIG. 1. Effect of annealing treatments on hardness and tensile properties of materials initially treated to states I, II, and III, and ECAP deformed to a strain of 4.2: (a) hardness evolution on annealing at $250{ }^{\circ} \mathrm{C}$, (b) hardness evolution on annealing $1 \mathrm{~h}$ at given temperature, and (c, d) yield stress and ductility evolution on annealing $1 \mathrm{~h}$ at each temperature.

temperatures. It is seen that there is little hardness change for anneals below $200{ }^{\circ} \mathrm{C}$, with large hardness falls for anneals at $250-300{ }^{\circ} \mathrm{C}$, and a stabilization of hardness at very high temperatures, $350{ }^{\circ} \mathrm{C}$ and above, at a level which is about the same for all material states. Again, material III shows a faster fall in hardness, and to lower values for most of the temperature range, than materials I and II, which maintain hardnesses very close to each other. The yield stress [Fig. 1(c)] shows changes very similar to those of hardness, namely a rapid fall in the 200-300 ${ }^{\circ} \mathrm{C}$ range, with material III softening more than materials I and II. Materials I and II are generally very similar, in line with the idea of dissolution of $\beta^{\prime \prime}-\beta^{\prime}$ precipitates in material II during deformation, and any differences of strength or hardness found between material I and material II are always very small.

The evolution of tensile ductility with annealing temperature is shown in Fig. 1(d), where it is seen that there are generally only slight changes as annealing occurs, and the ductility remains generally close to the asdeformed level of about $7 \%$. There are two exceptions to this generalization. (i) Material II shows a low ductility in the as-deformed state, for reasons that cannot be explained since it is argued that the $\beta^{\prime \prime}-\beta^{\prime}$ needles of the initially aged state are dissolved by the severe plastic deformation and materials in states I and II have similar particle and deformation structures after ECAP. A possible explanation of the low ductility of material II after ECAP may be an inhomogeneous structure induced during particle shearing, but microstructural examination provided no evidence of this. (ii) Material III shows a significant increase in ductility, above $10 \%$, after annealing at $250{ }^{\circ} \mathrm{C}$ and above, which seems to be related to the greater softening which this material demonstrates.

The influence of amount of prior strain on changes of tensile properties during annealing is illustrated in Fig. 2, for materials in initial states I, II, and III, and after $1 \mathrm{~h}$ anneals at $200{ }^{\circ} \mathrm{C}$. The yield stress of deformed material is seen to increase rapidly with increases in the amount of prior strain and tends to a steady state, saturated level after many ECAP passes: this applies for all initial states, I [Fig. 2(a)], II [Fig. 2(b)], and III [Fig. 2(c)]. This nearstabilization of mechanical properties after the highest strain level is consistent with the earlier remarks made that even though extremely high strain levels are required for complete structural (and property) stabilization, after strain levels of the order of 4-5, the structure (and properties) are already close to stabilization. ${ }^{8}$

The actual hardening behavior during ECAP is quite different for materials I, II, and III, even though the final properties of all are quite similar. This reflects the different starting microstructures of each and the similar final deformation microstructure for all. Thus, material I has $\mathrm{Mg}$ and $\mathrm{Si}$ solution hardening initially with only intermetallic dispersoid particles and hardens significantly during ECAP. Material II is initially very hard because of the $\beta^{\prime \prime}-\beta^{\prime}$ precipitates and so hardens only slightly during ECAP. Material III is initially very soft and contains intermetallic dispersoids and coarse $\beta$ precipitates; hence it hardens very greatly during ECAP. It 


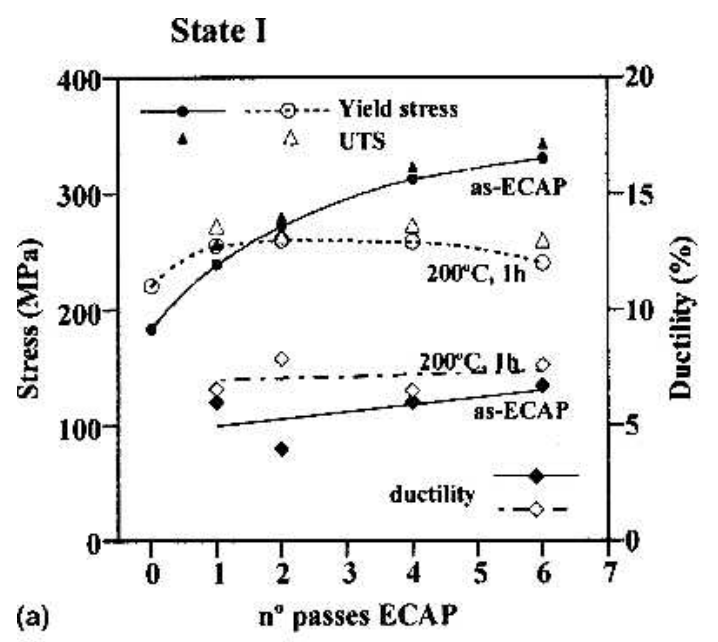

(a) State II

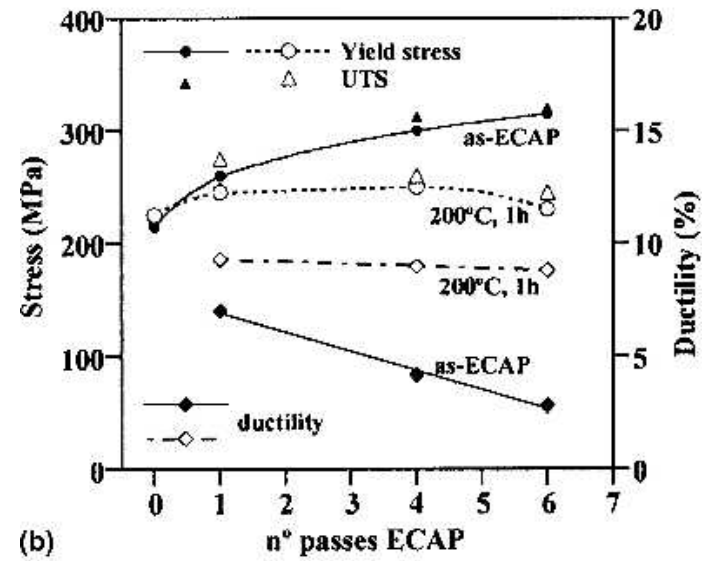

State III

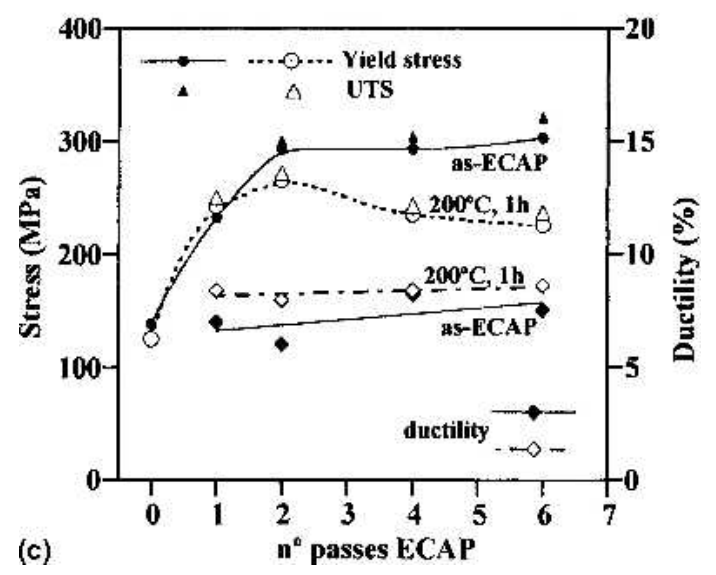

FIG. 2. Effect of amount of prior ECAP strain (number of passes, each pass imposing a true strain of about 0.7 ) on yield stress, ultimate tensile stress, and tensile ductility for materials initially treated to states I, II, and III. The influence of a $1 \mathrm{~h}$ anneal at $200{ }^{\circ} \mathrm{C}$ on tensile behavior is also shown.

would appear that material hardening is significantly controlled by fine precipitates and the ECAP-produced deformation substructures, while the role of intermetallic dispersoids alone is similar to that of such dispersoids together with additional coarse $\beta$ particles.
All materials show a small amount of work hardening during the tensile test itself, reaching the maximum stress after about $1 \%$ plastic strain, with the applied stress subsequently falling approximately linearly with tensile strain until final fracture, at strain levels of the order of $5 \%$. Hence, as shown in Fig. 2, the maximum tensile strength is only slightly greater than the yield stress. In general, the ductility of ECAP deformed material changes only little with amount of prior strain, except for initial state II, where there is a steady decrease in tensile ductility with amount of strain. As mentioned above, the reason for this steady fall in ductility is not understood and may perhaps be related to an inhomogeneous deformation structure induced during particle shearing, but there was no microstructural evidence of such inhomogeneity. The influence of annealing at $200{ }^{\circ} \mathrm{C}$ after ECAP straining is seen to be generally a fall of yield and tensile stress, with this fall being greater after more extensive prior straining. It is only for the initially solutionized material $\mathrm{I}$ in the undeformed state and after a single ECAP pass that precipitation hardening is greater than recovery softening, and hence there is an increase in yield stress. The general influence of annealing on ductility is to bring about a small increase, for example from about $5 \%$ to $7 \%$ for material I and from about 7\% to $8 \%$ for material III. Material II, which showed very low ductility after large amounts of prior ECAP strain, shows its ductility increased to about the same levels $(8 \%)$ by the anneal.

\section{Evolution of particle and grain structure of severely deformed materials on annealing}

The evolution of grain structure during annealing after ECAP is illustrated in Fig. 3. Here, the elongated and fine grain structure typical of the as deformed state is gradually replaced by a slightly larger and almost equiaxed grain structure. Already after an anneal of $1 \mathrm{~h}$ at $200{ }^{\circ} \mathrm{C}$ the grain shape is almost equiaxed, and the grain size increases steadily, but without very large changes up to the highest temperatures studied. Very similar changes, and grain sizes, were observed for all materials (I, II, and III). In these micrographs, many rather large bright particles are seen: these are the intermetallic particles that remain unsheared by ECAP, have an average size of $135 \mathrm{~nm}$, and are present in a volume fraction of $0.5 \%$ (see Table I). The spatial distribution of these intermetallic particles is not completely uniform across the samples studied. Occasional bands, some tens of microns thick, 100-200 $\mu \mathrm{m}$ long, and separated by 100-200 $\mu \mathrm{m}$, were observed where the density of intermetallic particles was greater (about double) that of the average material value. Such weakly banded structures may reflect the distribution of the transition metals $(\mathrm{Cr}, \mathrm{Fe}, \mathrm{Mn})$ remaining from the casting of the commercial material but are not 

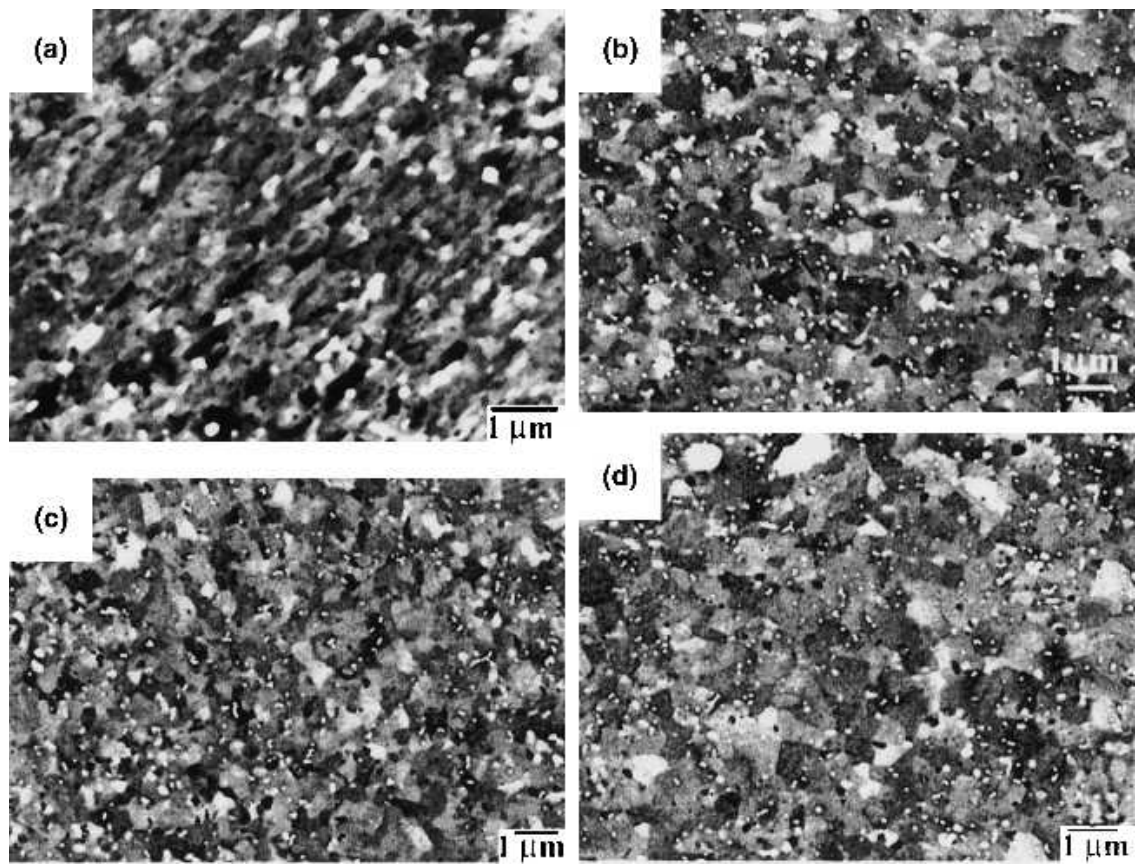

FIG. 3. Effect of annealing on grain morphology and size; backscattered electron images in SEM. The case illustrated is for material II (a) as-ECAP-deformed to a strain of 4.2 and subsequently annealed for $1 \mathrm{~h}$ at (b) $200{ }^{\circ} \mathrm{C}$, (c) $250{ }^{\circ} \mathrm{C}$, and (d) $300{ }^{\circ} \mathrm{C}$.

TABLE I. Volume fractions and sizes of particles, yield stress, and Orowan stress contribution, and grain sizes in ECAP-deformed and subsequently heat-treated materials. Heat treatments refer to $1 \mathrm{~h}$ at temperature. Particles present are stable intermetallics (IM) and fine precipitates $\left(\beta_{\mathrm{P}}\right)$ (in materials I and II) and stable intermetallics (IM), coarse $\beta$ phase particles $\left(\beta_{\mathrm{C}}\right)$, and fine precipitates $\left(\beta_{\mathrm{P}}\right)$ (in material III). The column labelled "Measured grain size" shows also, for a few cases, that a fraction of the total volume was composed of grains of much larger size (see text for details). Stable grain sizes calculated are Zener value $\left(D_{Z}\right)$ and a smaller value deduced considering stronger particle pinning $\left(D_{S}\right)($ see text for details).

\begin{tabular}{|c|c|c|c|c|c|c|c|c|c|c|}
\hline \multirow{2}{*}{$\begin{array}{l}\text { Material and } \\
\text { annealed state }\end{array}$} & \multicolumn{3}{|c|}{$\begin{array}{l}\text { Volume fraction } \\
\text { of particles }(\%)\end{array}$} & \multicolumn{3}{|c|}{$\begin{array}{l}\text { Average particle } \\
\text { size }(\mathrm{nm})\end{array}$} & \multirow{2}{*}{$\begin{array}{l}\text { Measured } \\
\text { yield stress } \\
\quad(\mathrm{MPa})\end{array}$} & \multirow{2}{*}{$\begin{array}{l}\text { Calculated } \\
\text { Orowan stress } \\
\left(\sigma_{\mathrm{OR}}\right)(\mathrm{MPa})\end{array}$} & \multirow{2}{*}{$\begin{array}{l}\text { Grain size }(\mu \mathrm{m}) \\
\text { In brackets fraction } \\
\text { of large grains }\end{array}$} & \multirow{2}{*}{$\begin{array}{c}\text { Stable grain size }(\mu \mathrm{m}) \\
\text { (See text for details) } \\
D_{\mathrm{Z}}-D_{\mathrm{S}}\end{array}$} \\
\hline & $\mathrm{IM}$ & $\beta_{\mathrm{C}}$ & $\beta_{P}$ & $\mathrm{IM}$ & $\beta_{\mathrm{C}}$ & $\beta_{\mathrm{P}}$ & & & & \\
\hline I (ECAP) & 0.5 & $\cdots$ & $\cdots$ & 135 & $\cdots$ & $\cdots$ & 330 & 14 & 0.25 & $36-4.5$ \\
\hline $\mathrm{I}+200^{\circ} \mathrm{C}$ & 0.5 & $\cdots$ & 1.5 & 135 & $\cdots$ & 85 & 256 & 53 & 0.32 & $6.2-0.78$ \\
\hline $\mathrm{I}+250^{\circ} \mathrm{C}$ & 0.5 & $\cdots$ & 1.5 & 135 & $\cdots$ & 100 & 211 & 48 & 0.40 & $7.2-0.89$ \\
\hline $\mathrm{I}+300^{\circ} \mathrm{C}$ & 0.5 & $\cdots$ & 1.5 & 135 & $\cdots$ & 100 & 183 & 48 & $\begin{array}{c}0.7 \\
\text { (also } 25 \% \text { of } 2.0 \text { ) }\end{array}$ & $7.2-0.89$ \\
\hline II (ECAP) & 0.5 & $\cdots$ & $\cdots$ & 135 & $\cdots$ & $\cdots$ & 316 & 14 & 0.3 & $36-4.5$ \\
\hline $\mathrm{II}+200^{\circ} \mathrm{C}$ & 0.5 & $\cdots$ & 1.5 & 135 & $\cdots$ & 80 & 233 & 54 & 0.37 & $6.0-0.74$ \\
\hline $\mathrm{II}+250^{\circ} \mathrm{C}$ & 0.5 & $\cdots$ & 1.5 & 135 & $\cdots$ & 95 & 208 & 49 & 0.40 & $6.8-0.85$ \\
\hline $\mathrm{II}+300^{\circ} \mathrm{C}$ & 0.5 & $\ldots$ & 1.5 & 135 & $\cdots$ & 110 & 171 & 45 & 0.63 & 7.6-0.96 \\
\hline III (ECAP) & 0.5 & 0.9 & $\cdots$ & 135 & 500 & $\cdots$ & 309 & 20 & 0.35 & $24-3.0$ \\
\hline $\mathrm{III}+200^{\circ} \mathrm{C}$ & 0.5 & 0.9 & 0.5 & 135 & 610 & 70 & 227 & 44 & 0.46 & $11-1.35$ \\
\hline $\mathrm{III}+250^{\circ} \mathrm{C}$ & 0.5 & 0.9 & 0.5 & 135 & 680 & 75 & 178 & 41 & $\begin{array}{c}0.43 \\
\text { (also } 25 \% \text { of } 0.74 \text { ) }\end{array}$ & $11.4-1.4$ \\
\hline $\mathrm{III}+300^{\circ} \mathrm{C}$ & 0.5 & 0.9 & 0.5 & 135 & 800 & 85 & 134 & 38 & $\begin{array}{c}0.74 \\
\text { (also } 50 \% \text { of } 3.2 \text { ) }\end{array}$ & $12.4-1.56$ \\
\hline
\end{tabular}

expected to play a significant role in defining microstructures or mechanical properties in view of their weak intensity and coarse scale. After the high temperature anneals (see below) many fine precipitates formed, but these are not clearly seen in Fig. 3 since they had a dark contrast in the SEM backscattered electron image and were smaller than the intermetallic particles. The only material with different appearance in the SEM is material III, which had many large $\beta$ precipitates, of size $0.5 \mu \mathrm{m}$ and present in a volume fraction of $0.9 \%$, with dark contrast due to the high $\mathrm{Mg}$ content.

Studies by TEM using electron diffraction and Kikuchi patterns to identify orientations of many grains have shown that the majority of boundaries present in the 
as-deformed state are HAGB [probably more precisely medium angle grain boundaries (MAGB)] and the average boundary misorientation is about $20^{\circ 22}$ : importantly for subsequent strength analyses, the fraction of LAGB is relatively low, of the order of one third of the total boundaries. A few examinations of boundary misorientations after annealing showed that the fraction of HAGB was even higher than for materials in the as-deformed state.

Grain sizes, reported as diameter of the equivalent circular grain, are shown in Table I for the three initial states, severely deformed by ECAP to a strain of 4.2 and then annealed. These values were determined from the measurement of several hundred grains in each case, using SEM backscattered electron images: values were also confirmed by measurements of TEM images. The grain size is seen to increase from the initial value of 0.25 $0.35 \mu \mathrm{m}$ (depending on initial state) to $0.65-0.75 \mu \mathrm{m}$ (depending on initial state) after annealing at $300{ }^{\circ} \mathrm{C}$. Figure 4 shows histograms of grain size for some of the heat treated states of Fig. 3. The grain size distribution is expected to be log-normal and not to change from this as the grain size increases by growth or coarsening during annealing. ${ }^{15,25}$ The results of Fig. 4 are fully consistent with this statement. The evolution of average grain size with temperature is also shown in Fig. 4. At the highest temperature, seen for materials I and III at $300{ }^{\circ} \mathrm{C}$, and also for material III at $250{ }^{\circ} \mathrm{C}$, but not for material II, a fraction of the grains had grown to a much larger size, about 2-4 times the average size of the finer grained matrix. For the particular heat treatment conditions examined, only a few percent of the grains present had grown in this way, and they occupied some $25-50 \%$ of the total volume, depending on the material state and anneal considered. These cases are reported in Table I, in brackets in the column defining grain size, and indicating also the volume fraction occupied by these large grains. This observation suggests that a discontinuous coarsening/recrystallization process is taking place and some grains are growing rapidly, ${ }_{15,25}$ while the majority of the grains are coarsening only slowly. It should be noted that the histograms of Fig. 4 were determined from the continuously coarsened/recrystallized fraction only, but also that no discontinuously grown grains were seen for state II.

Detailed grain and dislocation structures of deformed materials and after annealing are illustrated in Fig. 5. The as-deformed state, for all materials I, II, and III, shows elongated grains with a high density of dislocations, both at/in the boundaries and dispersed through the grain interiors. This is seen in both the bright-field and the weak-beam images of Figs. 5(a)-5(b). Annealing for $1 \mathrm{~h}$
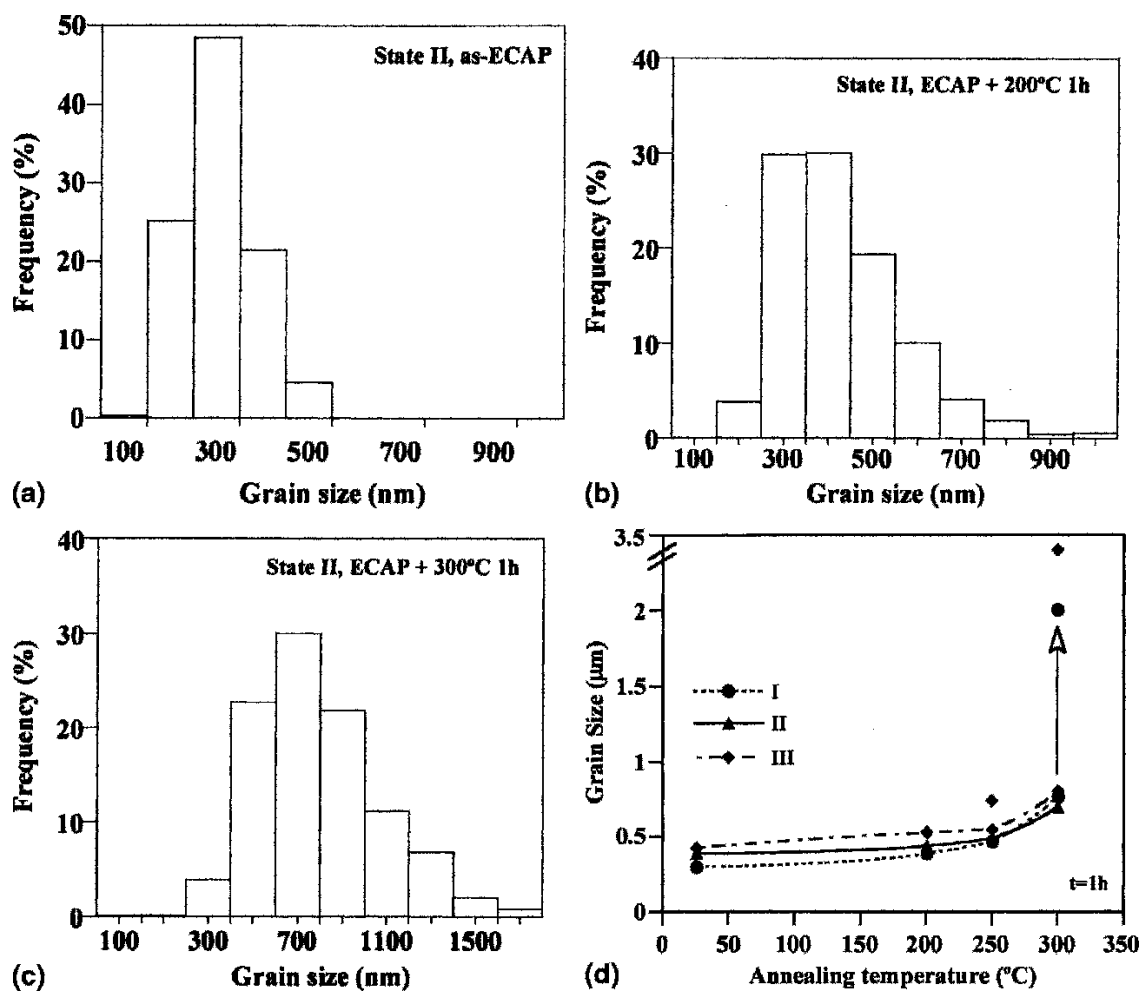

FIG. 4. Histograms showing the distribution of grain sizes for material II: (a) deformed to a strain of 4.2 by ECAP, and subsequently annealed for $1 \mathrm{~h}$ at (b) $200{ }^{\circ} \mathrm{C}$ or (c) $300{ }^{\circ} \mathrm{C}$. (d) Evolution of grain size with annealing temperature. Materials I and III show discontinuous grain coarsening at $300{ }^{\circ} \mathrm{C}$, as does material III at $250{ }^{\circ} \mathrm{C}$; here a small fraction of the grains grow to much a larger size than the average value for that state, as indicated by the arrow to the large grain sizes. 

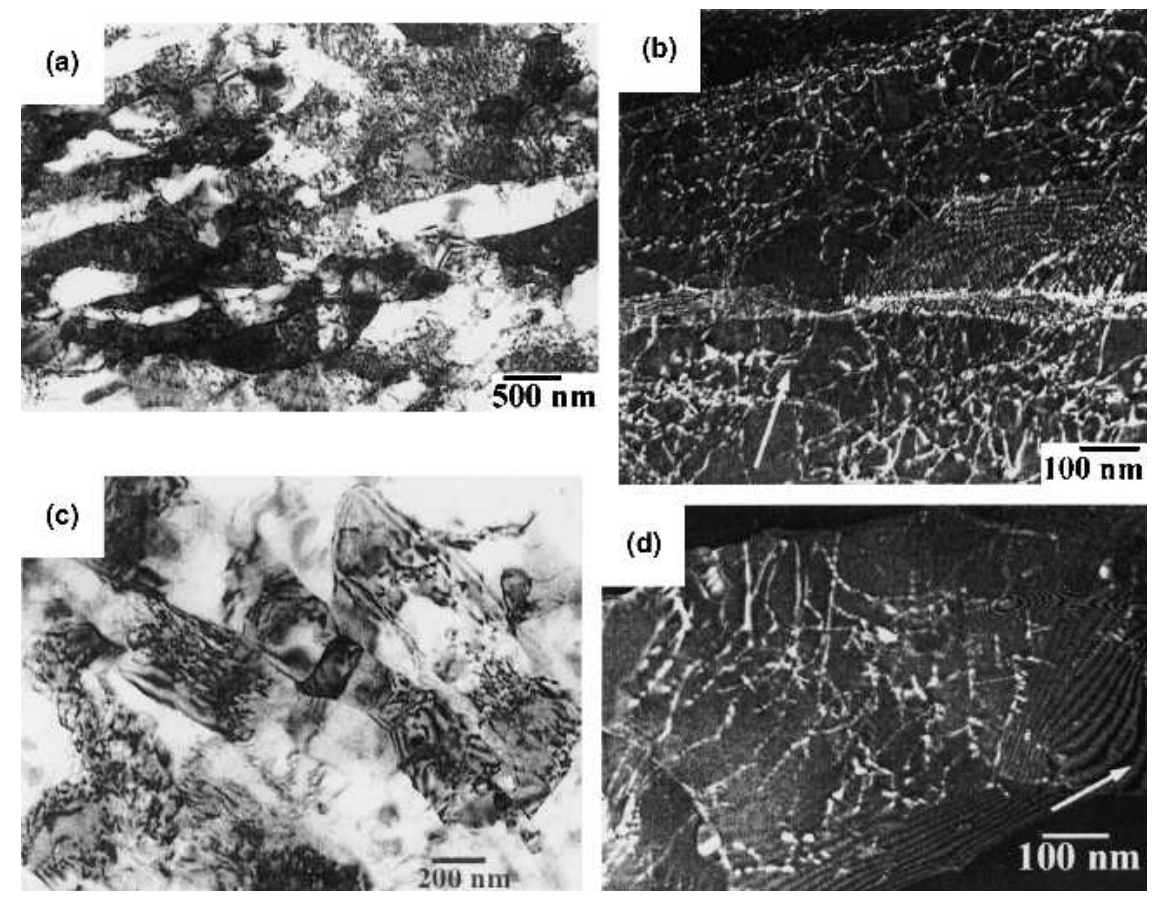

FIG. 5. Transmission electron micrographs taken in (a, c) bright field and in (b, d) weak beam showing grain and dislocation structures in material II: (a, b) as deformed by ECAP and (c, d) after annealing $1 \mathrm{~h}$ at $200{ }^{\circ} \mathrm{C}$. Bright-field images show changing contrast from the various grains and subgrains present. The weak beam images were taken using an imaging condition close to $\mathbf{g}: 4 \mathbf{g}$, where the imaging vector $\mathbf{g}$ is of type 111 (marked with an arrow).

at $200{ }^{\circ} \mathrm{C}$ leads to some thickening of grains, possibly some shortening of the initially elongated, ribbon-grain structure, and a significant reduction of dislocation density [see Figs. 5(c)-5(d)]. Shortening of elongated ribbonlike grains produced by ECAP deformation has been shown to be possible, ${ }^{9,23}$ presumably as surface tension effects of low angle transverse boundaries lead to ribbon break-up by pinching off into shorter grain segments. Further annealing leads to continued grain growth and a reduction in the density of loosely arranged dislocations inside the subgrains to negligible values. The bright-field images of Figs. 5(a) and 5(c) are typical of those of severely deformed materials showing a very high dislocation density inside the subgrains, too many to distinguish clearly and attempt counting. For this reason, the weak beam images shown [Figs. 5(b) and 5(d)] are important in providing sharper dislocation contrast at higher magnification and allowing measurement of densities of dislocations inside the subgrains. Measurement of a characteristic dislocation density nevertheless remains difficult, both because of variations of density from grain to grain, and because of the large errors associated with determination of foil thickness. Values of $1-2 \times 10^{15} / \mathrm{m}^{2}$ and $1-2 \times 10^{14} / \mathrm{m}^{2}$ have been determined for as ECAP deformed materials and for materials annealed $1 \mathrm{~h}$ at $200{ }^{\circ} \mathrm{C}$, respectively. No obvious change of density was found on comparing materials I, II, and III in either the deformed or the $200{ }^{\circ} \mathrm{C}$ annealed states.
The morphology, size, and distribution of particles on aging after ECAP are illustrated by the TEM photographs of Fig. 6. As mentioned earlier, in all materials, there was $0.5 \%$ by volume of intermetallic particles of size $135 \mathrm{~nm}$, which were the only particles present in the solutionized material I (see Table I; the light particles are also seen in Fig. 3). These particles were not affected by the severe plastic deformation nor by subsequent anneals since they were composed of stable intermetallics and low diffusion elements. Fine needle $\beta^{\prime \prime}-\beta^{\prime}$ particles in material II were sheared and dissolved by severe plastic deformation such that the precipitate content of both materials I and II was identical after ECAP (see Table I). (The previous statement remains valid for the several thin foil samples and areas that were examined by TEM, despite the arguments to the contrary made during the analysis of mechanical property variations.) The coarse $\beta$ particles originally in material III were sheared by ECAP to elongated, slightly smaller particles, occupying $0.9 \%$ by volume and of size $500 \mathrm{~nm}$ (see Table I). The dispersoid particles present in all materials are illustrated in Fig. 6(a), showing material III deformed to a strain of 4.2. The large, widely spaced $\beta$ particles are not seen in this figure.

On aging at $200-300{ }^{\circ} \mathrm{C}$, precipitation of fine, equiaxed particles occurs for all materials; for materials I and II, this is due to the precipitation of all the solute in the alloy ( $1 \mathrm{wt} \% \mathrm{Mg}$ and $1 \mathrm{wt} \% \mathrm{Si}$ ) down to the solubility 

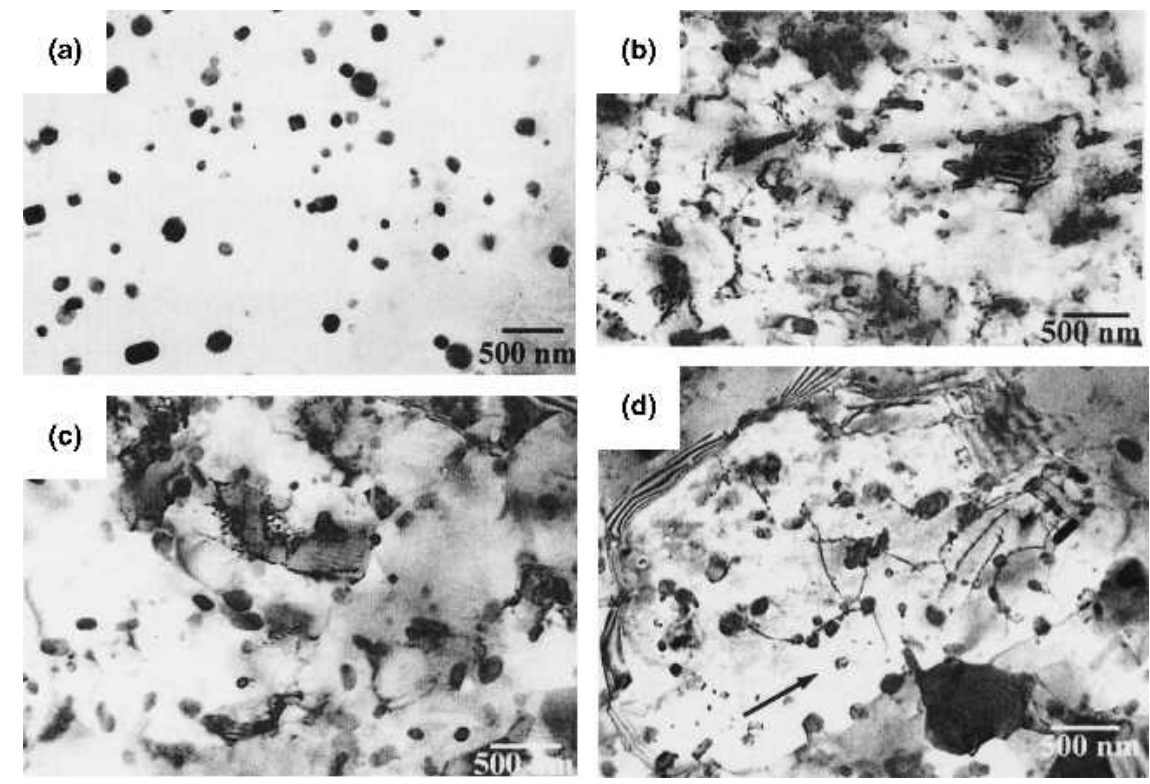

FIG. 6. Transmission electron microscope bright-field images showing particles in material III deformed to a strain of 4.2 by ECAP: (a) as-deformed material, showing slightly elongated intermetallic particles, and material annealed $1 \mathrm{~h}$ at (b) $200{ }^{\circ} \mathrm{C}$, (c) $250{ }^{\circ} \mathrm{C}$, and (d) $300{ }^{\circ} \mathrm{C}$. Precipitate and grain growth occur during the $200-300{ }^{\circ} \mathrm{C}$ anneals. (a, b, c) Taken under kinematic diffraction contast conditions, showing several grains/subgrains under different contrast. (d) Single grain imaged with a 111 type diffraction vector (shown by arrow) and a moderate dislocation density.

level characteristic of the aging temperature. For material III, the precipitation is due to the rejection of the solute corresponding to the solubility differences between the initial $450{ }^{\circ} \mathrm{C}$ anneal and the final $200-300{ }^{\circ} \mathrm{C}$ anneals. The new precipitates are always equiaxed in shape and do not show the needle morphology characteristic of precipitation of $\beta^{\prime \prime}$ and $\beta^{\prime}$ phases. When they were extremely fine it was not possible to determine either chemical composition [by energy dispersive spectroscopy (EDS)] or crystal structure (by TEM diffraction), but when they grew to larger size, they appeared to be $\beta$ phase particles. Figures 6(b)-6(d) show the formation and growth of these fine particles, of average size 70-100 $\mathrm{nm}$ in these micrographs, as well as the presence of the unchanging intermetallic particles and the steady growth of the grains. As discussed in the previous paragraphs, the grain size for this material III increased from $0.35 \mu \mathrm{m}$ in the deformed state to $0.74 \mu \mathrm{m}$ after annealing at $300{ }^{\circ} \mathrm{C}$ [Fig. 6(d)]. Figure 6(d) also shows how some grains in the material annealed at $300{ }^{\circ} \mathrm{C}$ have grown to a much larger size of several microns. Table I gives average values of the sizes of the various particles in each material after annealing, determined by quantitative analysis of several hundreds of particles in SEM and TEM images, as well as the volume fraction of each type. The values of volume fraction are determined experimentally, as described in Sec. II, from analysis of SEM and TEM photographs (intermetallics and coarse $\beta$ phase particles in material III) or from the solubility limits in the $\mathrm{Al}-\mathrm{Mg}-\mathrm{Si}$ phase diagram (fine $\beta$ phase particles in materials I-II-III during the $200-300{ }^{\circ} \mathrm{C}$ anneal).

\section{DISCUSSION}

\section{A. Precipitation and grain growth}

As seen in previous studies of precipitation sequence after severe plastic deformation, ${ }^{26}$ the formation and growth of precipitates is completely different here compared with the behavior found in conventional solutionised and aged $\mathrm{Al}-\mathrm{Mg}-\mathrm{Si}$ alloys. ${ }^{35} \mathrm{In}$ such materials, fine needles of $\beta^{\prime \prime}$ and $\beta^{\prime}$ precipitates are observed on annealing before the stable $\beta$ phase eventually forms. The reason for the choice of such metastable precursors is usually the lower misfit at the near-coherent matrixprecipitate interface that allows easier, more rapid nucleation. The presence of a very high dislocation density after severe plastic deformation clearly offers many easy nucleation sites and rapid nucleation, apparently of the stable $\beta$ phase, and rapid growth with solute transfer along dislocation pipes, can occur with preference for the stable, equiaxed phase over any metastable variant.

The question of whether the $\beta^{\prime \prime}-\beta^{\prime}$ needles present in the solutionized and peak aged material II are truly completely dissolved or whether they are simply sheared to a small size, too difficult to detect, deserves some consideration. TEM studies both after many ECAP passes and after only one pass through the ECAP die (imposed strain of 0.7 ) failed to find any remnants of broken needles and thus confirm the argument that such fine $\beta^{\prime \prime}-\beta^{\prime}$ needles are completely dissolved during severe deformation (to strains of 4.2). Furthermore, when comparing materials I and II, extremely similar behavior is observed throughout (particle and grain sizes in Table I and Fig. 4, hardness 
and strength in Table I and Figs. 1 and 2). An important difference to be emphasized between the present study (and as reported in Ref. 22) and other reported studies, where precipitates have been sheared but not dissolved, ${ }^{11,18,19,21}$ is that the needle precipitates in undeformed material II are extremely thin, only $6 \mathrm{~nm}$ thick, and more easily destabilized by shearing. The mechanical properties of ECAP-deformed materials I and II are also generally similar (Figs. 1 and 2), confirming the close similarity of the particle distribution and deformation structures of the two materials after severe plastic deformation.

On annealing the severely deformed materials, the grains simply grow (or show continuous recrystallization). Despite the very high retained dislocation density, there is no sign of new grain nucleation or more rapid growth of selected grains, relative to the surrounding neighbours, at any of the lower annealing temperatures. The only processes occurring are those of dislocation recovery and gradual grain growth. At very high temperatures, when essentially all loosely arranged dislocations inside the subgrains have been lost, processes of discontinuous grain growth are seen to occur. Such discontinuous grain growth ${ }^{14,15}$ may be associated with particle coarsening and changes in the size and distribution of the particles, ${ }^{25}$ even though this growth is a gradual and slow process at the temperatures examined (200$\left.300{ }^{\circ} \mathrm{C}\right)$. Similar discontinuous grain growth has been observed previously on annealing severely deformed materials, some with and others without second phase particles, ${ }^{3,9,17,36}$ and may instead be explained by the inherently unstable grain structure when many of the boundaries are LAGB. ${ }^{36}$

In the presence of a uniform and stable distribution of particles, the stable grain size that may be retained may be written as $D_{\mathrm{Z}} \approx 4 / 3(\phi / f)$, or some similar expression, ${ }^{25,37-40}$ where $D_{Z}$ is the stabilized grain size, $\phi$ the particle size, and $f$ its volume fraction. Other estimates have given lower stable grain sizes, for example, down to $D_{\mathrm{S}} \approx \phi / 6 f$, for larger volume fractions of particle phase or when the particles and grain boundaries are not randomly distributed. In a recent study of grain growth in a severely deformed particle-containing $\mathrm{Al}$ alloy, ${ }^{25}$ it was shown that grain boundary pinning occurred leading to a stable grain size near this second, lower value. Table I shows values of Zener grain size, i.e., $D_{\mathrm{Z}} \approx 4 / 3(\phi / f)$, as well as the lower grain size value, i.e., $D_{\mathrm{S}} \approx \phi / 6 f$, for the present materials, representing what can be considered as upper-bound and lower-bound estimates of the stable grain size controlled by particle pinning. It is clear that the as-deformed grain size is much smaller than these stabilized values and is determined by deformation (the balance of debris accummulation and dislocation recovery) and not by particle stabilization. The grain size after annealing (considering the continuously coarsening value, not the discontinuously coarsened value) approaches the lower value of stabilized grain size, but is still not very close at the end of the anneals. Humphrey et al. ${ }^{25}$ suggest that grain size stagnation will occur at the stabilized sizes above, and further growth beyond this grain size will occur only following particle coarsening. However, for conditions where the particle size is rather large for relatively fine grains (when the so-called dispersion parameter $f / \phi$ is low), the system can enter a region of unstable, discontinuous grain coarsening as some grain boundaries break away from their pinning particles to produce a few very large grains. Such a description appears to describe well the present situation at the highest annealing temperatures.

\section{B. Analysis of strengthening}

The analysis of strengthening here is complicated by the fact that there are many terms contributing to the total strength. In addition to strengthening by the dispersed intermetallic and precipitate particles, present in all deformed and annealed states, there is strengthening by the rather fine grain size and strengthening by the high density of loosely arranged dislocations inside the subgrains. The contribution of grain boundary strengthening also requires careful assessment in view of the relatively low misorientation angle across many of the boundaries.

The contribution of particles to strengthening has been calculated for each material and state using the Orowan strengthening model, i.e., considering that all particles are sufficiently large that they are not cut and dislocations bow around them. The Orowan strengthening $\left(\sigma_{\mathrm{O}}\right)$ is calculated as

$$
\sigma_{\mathrm{O}}=\frac{2 m G b}{(1.18) 4 \pi(\lambda-\phi)} \ln \left(\frac{\phi}{2 b}\right),
$$

where $m$ is the Taylor factor, taken as $3.1, G$ is the shear modulus (27 GPa), ${ }^{41} b$ is the Burgers vector $(0.284 \mathrm{~nm}),{ }^{41}$ and $\phi$ is the particle size. $\lambda$ is the interparticle spacing on the slip plane, calculated from the particle size and volume fraction $f$ as

$$
\lambda=\left(\frac{\pi}{6}\right)^{1 / 2}\left(\frac{\phi}{\sqrt{f}}\right) .
$$

The Orowan strength contribution has been calculated for each family of particles present in a given material: intermetallic particles present as $0.5 \%$ volume fraction, fine precipitates present as $1.5 \%$ or $0.5 \%$ volume fraction, and coarse $\beta$ precipitates in material III present as $0.9 \%$ volume fraction (see Table I). These strengthening contributions have been added linearly to estimate the total particle strengthening of a given material and annealed state (see Table I). A simple linear addition of 
strengthening contributions has been shown to be the best way of combining contributions for the case when a few strong obstacles are distributed with many weak obstacles. ${ }^{42}$ In the present case, we have a very small number of extremely large, strong particle obstacles (large $\beta$ phase particles in state III only), rather few mediumstrong obstacles (the intermetallic dispersed particles in all materials), and a much larger number of weak obstacles (the finer $\beta$ precipitates forming on ageing). As such, this simple linear addition of strengthening contributions seems a reasonable way of treating the present data.

Figure 7 shows the experimental yield stress $\sigma_{0.2}$ after subtraction of the Orowan stress $\sigma_{\mathrm{O}}$ in relation to the square root of the grain size $D$, i.e., plotted as a HallPetch representation. It is seen that all the data fall well on three parallel straight lines for the as-deformed materials, those annealed at $200{ }^{\circ} \mathrm{C}$ only, and those annealed at higher temperatures. The slope of the lines corresponding to the three annealing conditions is identical, with a value of $78 \mathrm{MPa} \mu \mathrm{m}^{1 / 2}$, while the intercepts on the stress axis have values of 163,70 , and $40 \mathrm{MPa}$, for the asdeformed, annealed at $200{ }^{\circ} \mathrm{C}$, and annealed at 250$300{ }^{\circ} \mathrm{C}$ states, respectively. For high purity $\mathrm{Al}$, a value of Hall-Petch slope of about $40 \mathrm{MPa} \mu \mathrm{m}^{1 / 2}$ has been suggested, ${ }^{33}$ while for less-pure $\mathrm{Al}$ or for $\mathrm{Al}-(2-3) \mathrm{Mg}$ higher slopes of about $70-170 \mathrm{MPa} \mu \mathrm{m}^{1 / 2}$ have been proposed. $^{31,43}$ The deduced value of Hall-Petch slope is in very good agreement with that expected for the present $\mathrm{Al}-\mathrm{Mg}-\mathrm{Si}$ alloy, with its low $\mathrm{Mg}$ content and little expected effect of Si solute, and especially after precipitation of virtually all the solute in all the aged or annealed materials.

A final point to consider when discussing such grain

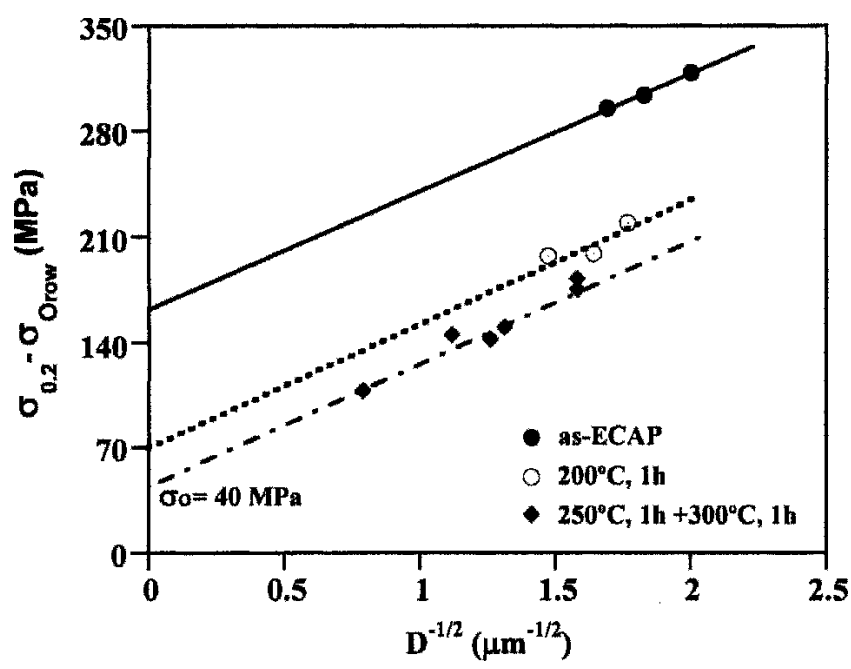

FIG. 7. Hall-Petch analysis relating the experimental yield stress after removal of the particle strengthening term $\left(\sigma_{0.2}-\sigma_{\text {Orow }}\right)$ to the grain size $D$, for materials I, II, and III, in the as-deformed state and after annealing at $200{ }^{\circ} \mathrm{C}$ and $250-300{ }^{\circ} \mathrm{C}$. size strengthening is that the boundaries in the deformed and the annealed materials have all been treated as HAGB. This is not completely true, as has been discussed earlier, since the average grain boundary misorientation is near $20^{\circ}$ in the deformed materials, independent of the prior state of precipitation, and approximately one third of the boundaries present are actually LAGB. For the annealed materials, where dislocation recovery and grain growth tends to increase somewhat the average boundary misorientation, treating all the boundaries as HAGB in the Hall-Petch analysis may be more reasonable. For the as-deformed materials, it may instead be better to consider strengthening by only approximately two thirds of the boundaries present, i.e., those that are HAGB: this consideration would lead to an increased Hall-Petch slope, to about $110 \mathrm{MPa} \mu \mathrm{m}^{1 / 2}$, leaving a similar intercept stress of about $160 \mathrm{MPa}$.

The intercept stress values of 40, 70, and $163 \mathrm{MPa}$ deduced from Fig. 7 can be associated with the matrix strength of commercially pure $\mathrm{Al}$ [annealed at 250$300{ }^{\circ} \mathrm{C}$, little remaining solute and few remaining dislocations, see Figs. 6(c)-6(d)], and the matrix strengths of this alloy containing dislocations inside the subgrains [see Figs. 5(b) and 5(d)]. The intercept stress increases of 30 and $123 \mathrm{MPa}$ (above the $40 \mathrm{MPa}$ baseline strength) may then be associated with the loosely arranged dislocations present inside the subgrains in these materials. Strengthening by a loose distribution of dislocations $\left(\sigma_{\rho}\right)$ may be analyzed using the Taylor equation

$$
\sigma_{\rho}=m \alpha G b \sqrt{\rho},
$$

where $\alpha$ is a constant of value approximately $0.1-0.3$, depending on the dislocations and configurations involved. For example, a value of $\alpha$ of 0.24 has recently been used for a similar analysis of dislocation strengthening in severely deformed materials. ${ }^{33}$ Using the Taylor equation to interpret the measured intercept stress increases (30 and $123 \mathrm{MPa}$ ) with values of $\alpha$ of $0.1-0.25$, we deduce dislocation densities in the $200{ }^{\circ} \mathrm{C}$ annealed and the as-deformed materials of $3 \times 10^{13}$ to $2 \times 10^{14} / \mathrm{m}^{2}$ and $4 \times 10^{14}$ to $3 \times 10^{15} / \mathrm{m}^{2}$, respectively. Such values are in excellent agreement with the values measured experimentally $\left(1-2 \times 10^{14} / \mathrm{m}^{2}\right.$ and $1-2 \times 10^{15} / \mathrm{m}^{2}$, Fig. 5). It should be emphasized at this point that the analysis above provides an excellent demonstration of the strengthening role of the loosely arranged dislocations observed inside the subgrains but should not be taken as quantitatively precise: the large extrapolation to the stress axis required from the three close data points of as-deformed materials implies a large uncertainty in any strength values.

This analysis confirms, as demonstrated recently for similarly heavily deformed materials, ${ }^{33,34}$ that it is necessary to take account of both boundary strengthening 

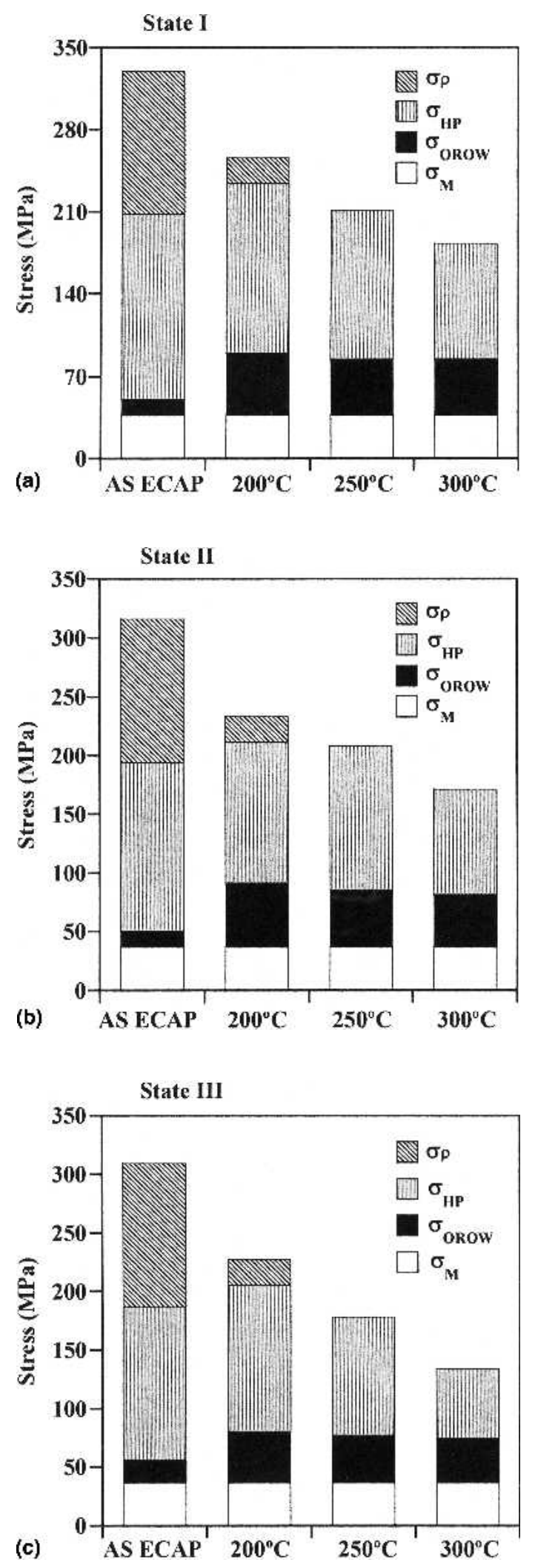

FIG. 8. Bar charts representing the strengthening contributions of dislocation hardening $\left(\sigma_{\rho}\right)$, hardening due to fine grain size $\left(\sigma_{\mathrm{HP}}\right)$, hardening due to dispersed particles $\left(\sigma_{\text {OROW }}\right)$, and matrix hardening $\left(\sigma_{\mathrm{M}}\right)$ for all three materials I, II, and III, in the as-ECAP-deformed state and after annealing for $1 \mathrm{~h}$ at 200,250 , and $300{ }^{\circ} \mathrm{C}$. and of strengthening by loosely arranged dislocations to explain the total strength of such materials (as well as any particle strengthening, if there are particles present). Figure 8 shows bar charts representing the strengthening contributions of each component to the total material strength, for all three materials (I, II, and III) from the as-deformed state to the well-annealed state. The three materials are seen to have almost identical strengthening contributions because the as-deformed grain and dislocation structures are essentially independent of the particles present, as are the changes to these on annealing; in addition, precipitation occurs in similar ways for all three materials on annealing at $200-300{ }^{\circ} \mathrm{C}$. The as-deformed materials are seen to be strong because of significant dislocation hardening and grain boundary hardening. Annealing quickly removes the dislocation hardening contribution but leaves grain boundary hardening and a particle hardening contribution.

\section{CONCLUSIONS}

Samples of a commercial Al-Mg-Si alloy have been severely deformed to a strain of 4.2 by ECAP in three states of prior heat treatment, corresponding to a solutionized state, a peak-aged state, and a well overaged state. In all cases, the grain structure produced is elongated and submicron in size, with a high density of loose dislocations inside the grains. The presence of various precipitates, with the stable intermetallic dispersoid particles, does not seem to affect the deformation microstructure.

On annealing, excess solute precipitates uniformly throughout all the materials, while dislocations are lost by recovery and grains spheroidize to an equiaxed morphology and grow uniformly and continuously at the low annealing temperatures.

At the higher annealing temperatures examined, a duplex grain structure appears by discontinuous grain coarsening. This appears to be associated with incomplete stabilization of the grain boundaries by the slowly coarsening precipitates.

Strengthening contributions due to the fine grain size and the high density of loosely arranged dislocations inside these grains have been analyzed and shown to be of about equal importance in as-deformed materials. Following annealing, the dislocation hardening contribution is quickly lost, while the grain boundary contribution falls as the grains coarsen. For the present materials, there is also a significant contribution of strengthening by the various dispersed particles.

\section{ACKNOWLEDGMENT}

We would like to acknowledge the financial support of the Comunidad de Madrid (CAM) under Contract No. 07N/0087/2002. 


\section{REFERENCES}

1. V.M. Segal: Materials processing by simple shear. Mater. Sci. Eng. A 197, 157 (1995).

2. V.M. Segal: Engineering and commercialization of equal channel angular extrusion (ECAE). Mater. Sci. Eng. A 386, 269 (2004).

3. J. Wang, Y. Iwahashi, Z. Horita, M. Furukawa, M. Nemoto, R.Z. Valiev, and T.G. Langdon: An investigation of microstructural stability in an $\mathrm{Al}-\mathrm{Mg}$ alloy with submicrometer grain size. Acta Mater. 44, 2973 (1996).

4. Y. Iwahashi, Z. Horita, M. Nemoto, and T.G. Langdon: An investigation of microstructural evolution during equal-channel angular pressing. Acta Mater. 45, 4733 (1997).

5. Y. Iwahashi, Z. Horita, M. Nemoto, and T.G. Langdon: Factors influencing the equilibrium grain size in equal-channel angular pressing: The role of $\mathrm{Mg}$ additions to aluminium. Metall. Mater. Trans. 29A, 2503 (1998).

6. R.Z. Valiev, R.K. Islamgaliev, and I.V. Alexandrov: Bulk nanostructured materials from severe plastic deformation. Prog. Mater. Sci. 45, 103 (2000).

7. J.S. Hayes, R. Keyte, and P.B. Prangnell: Effect of grain size on tensile behaviour of a submicron grained $\mathrm{Al}-3 \mathrm{wt} \% \mathrm{Mg}$ alloy produced by severe deformation. Mater. Sci. Technol. 16, 1259 (2000).

8. P.B. Prangnell, J.R. Bowen, and A. Gholinia: The formation of submicron and nanocrystalline grain structures by severe deformation, in Science of Metastable and Nanocrystalline Alloys: Structure, Properties and Modelling, edited by A.R. Dineson, M. Eldrup, J.D. Juul, S. Linderoth, T.B. Pedersen, and N.H. Pryds (Proc. 22nd Ris $\varnothing$ Int Symp, Ris $\emptyset$ National Lab, Roskilde, Denmark, 2001), p. 105.

9. D.G. Morris and M.A. Muñoz-Morris: Microstructure of severely deformed $\mathrm{Al}-3 \mathrm{Mg}$ and its evolution during annealing. Acta Mater. 50, 4047 (2002).

10. A. Gholinia, P.B. Prangnell, and M.V. Markushev: The effect of strain path on the development of deformation structures in severely deformed aluminium alloys processed by ECAE. Acta Mater. 47, 1115 (2000).

11. P.J. Apps, J.R. Bowen, and P.B. Prangnell: The effect of coarse second-phase particles on the rate of grain refinement during severe deformation processing. Acta Mater. 51, 2811 (2003).

12. J.Y. Chang and A. Shan: Microstructure and mechanical properties of AlMgSi alloys after equal channel angular pressing at room temperature. Mater. Sci. Eng. 347, 165 (2003).

13. M.V. Markushev and M.Yu. Murashkin: Structure and mechanical properties of commercial Al-Mg 1560 alloy after equal-channel angular extrusion and annealing. Mater. Sci. Eng. 367, 234 (2004).

14. F.J. Humphreys: Local lattice rotations at second phase particles in deformed metals. Acta Metall. 27, 180 (1979).

15. F.J. Humphreys and M. Hatherly: Recrystallization and Related Annealing Phenomena (Pergamon, Oxford, U.K., 1995).

16. K. Oh-ishi, Z. Horita, D.J. Smith, and T.G. Langdon: Grain boundary structure in $\mathrm{Al}-\mathrm{Mg}$ and $\mathrm{Al}-\mathrm{Mg}-\mathrm{Sc}$ alloys after equalchannel angular pressing. J. Mater. Res. 16, 583 (2001).

17. S. Lee, A. Utsunomiya, H. Akamatsu, K. Neishi, M. Furukawa, Z. Horita, and T.G. Langdon: Influence of scandium and zirconium on grain stability and superplastic ductilities in ultrafinegrained Al-Mg alloys. Acta Mater. 50, 553 (2002).

18. K. Oh-ishi, Y. Hasi, A. Sadakata, K. Kaneko, Z. Horita, and T.G. Langdon: Microstructural control on an $\mathrm{Al}-\mathrm{Mg}-\mathrm{Si}$ alloy using equal-channel angular pressing. Mater. Sci. Forum 396-402, 333 (2002).

19. C. Xu, M. Furukawa, Z. Horita, and T.G. Langdon: Using ECAP to achieve grain refinement, precipitate fragmentation and high strain rate superplasticity in a spray-cast aluminium alloy. Acta Mater. 51, 6139 (2003).
20. C. Xu, M. Furukawa, Z. Horita, and T.G. Langdon: Influence of ECAP on precipitate distributions in a spray-cast alumnium alloy. Acta Mater. 53, 749 (2005).

21. B.B. Straumal, B. Baretzky, A.A. Mazilkin, F. Phillipp, O.A. Kogtenkova, M.N. Volkov, and R.Z. Valiev: Formation of nanograined structure and decomposition of supersaturated solid solution during high pressure torsion of $\mathrm{Al}-\mathrm{Zn}$ and $\mathrm{Al}-\mathrm{Mg}$ alloys. Acta Mater. 52, 4469 (2004).

22. I. Gutierrez-Urrutia, M.A. Muñoz-Morris, and D.G. Morris: The effect of coarse second-phase particles and fine precipitates on microstructure refinement and mechanical properties of severely deformed Al alloy. Mater. Sci. Eng. A 394, 399 (2005).

23. P.B. Prangnell, J.S. Hayes, J.R. Bowen, P.J. Apps, and P.S. Bate: Continuous recrystallisation of lamellar deformation structures produced by severe deformation. Acta Mater. 52, 3193 (2004).

24. C.Y. Yu, P.L. Sun, P.W. Kao, and C.P. Chang: Evolution of microstructure during annealing of a severely deformed aluminium. Mater. Sci. Eng. 366, 310 (2004).

25. M. Ferry, N.E. Hamilton, and F.J. Humphreys: Continuous and discontinuous grain coarsening in a fine grained particlecontaining Al-Sc alloy. Acta Mater. 53, 1097 (2005).

26. Y.H. Zhao, X.Z. Liao, Z. Jin, R.Z. Valiev, and Y.T. Zhu: Microstructures and mechanical properties of ultrafine grained $7075 \mathrm{Al}$ alloy processed by ECAP and their evolutions during annealing. Acta Mater. 52, 4589 (2004).

27. R.Z. Valiez, I.V. Alexandrov, Y.T. Zhu, and T.C. Lowe: Paradox of strength and ductility in metals processed by severe plastic deformation. J. Mater. Res. 17, 5 (2002).

28. M. Furukawa, Z. Horita, M. Nemoto, R.Z. Valiev, and T.G. Langdon: Factors influencing the flow and hardness of materials with ultrafine grain sizes. Philos. Mag. 78A, 203 (1998).

29. M. Furukawa, Y. Iwahashi, Z. Horita, M. Nemoto, N. Tsenev, R.Z. Valiev, and T.G. Langdon: Structural evolution and the HallPetch relationship in an $\mathrm{Al}-\mathrm{Mg}-\mathrm{Li}-\mathrm{Zr}$ alloy with ultra-fine grain size. Acta Mater. 45, 4751 (1997).

30. R.Z. Valiev: Structure and mechanical properties of ultrafinegrained metals. Mater. Sci. Eng. A 234-236, 58 (1997).

31. M.A. Muñoz-Morris, C. Garcia Oca, and D.G. Morris: Mechanical behaviour of dilute $\mathrm{Al}-\mathrm{Mg}$ alloy processed by equal channel angular pressing. Scr. Mater. 48, 213 (2003).

32. M.A. Muñoz-Morris, C. Garcia Oca, G. Gonzalez-Doncel, and D.G. Morris: Microstructure and mechanical properties of severely deformed $\mathrm{Al}-3 \mathrm{Mg}$ and its evolution during subsequent annealing treatments, in Nanomaterials by Severe Plastic Deformation, Fundamentals-Processing-Applications, edited by M.J. Zehetbauer and R.Z. Valiev (Wiley-VCH, Weinheim, Germany, 2004), p. 623.

33. J.R. Bowen, P.B. Prangnell, D. Juul Jensen, and N. Hansen: Microstructural parameters and flow stress in $\mathrm{Al}-0.13 \% \mathrm{Mg}$ deformed by ECAE processing. Mater. Sci. Eng. A 387-389, 235 (2004).

34. N. Hansen: Hall-Petch relation and boundary strengthening. Scripta Mater. 51, 801 (2004).

35. G.A. Edwards, K. Stiller, G.L. Dunlop, and M.J. Couper: The precipitate sequence in Al-Mg-Si alloys. Acta Mater. 46, 3893 (1998).

36. F.J. Humphreys, P.B. Prangnell, J.R. Bowen, A. Gholinia, and C. Harris: Developing stable fine-grain microstructures by large strain deformation. Philos. Trans. R. Soc. London B Biol. Sci. A 357, 1663 (1999).

37. C. Zener: Private communication to C.S. Smith. Trans. Amer. Inst. Min. Metall. Eng. 175, 15 (1949).

38. T. Gladman: On the theory of the effect of precipitate particles on grain growth in metals. Proc. R. Soc. 284A, 298 (1966). 
39. P.R. Rios: A theory for grain boundary pinning by particles. Acta Metall. 35, 2805 (1987).

40. G.N. Hassold, E.A. Holm, and D.J. Srolovitz: Effects of particle size on inhibited grain growth. Scripta Metall. Mater. 24, 101 (1990).

41. O.R. Myhr, O. Grong, and S.J. Andersen: Modelling of the age hardening behaviour of $\mathrm{Al}-\mathrm{Mg}-\mathrm{Si}$ alloys. Acta Mater. 49, 65 (2001).

42. L.M. Brown and R.K. Ham: Dislocation-particle interactions, in
Strengthening Methods in Crystals, edited by A. Kelly and R.D. Nicholson (Elsevier, Amsterdam, The Netherlands, 1971), Chap. 2, p. 8.

43. R.W. Armstrong and R.M. Douthwaite: Hall-Petch basis for assessing alloy strengthening, in Grain Size and Mechanical Properties-Fundamentals and Applications, edited by M.A. Otooni, R.W. Armstrong, N.J. Grant, and K. Ishizaki (Mater Res Soc Symp Proc. 362, Pittsburgh, PA, 1995), p. 41. 